\title{
Surrounding rock deformation and stress evolution in pre-driven longwall recovery rooms at the end of mining stage
}

\author{
Bonan Wang ${ }^{1}\left(\mathbb{D} \cdot\right.$ Faning Dang ${ }^{1} \cdot$ Wei Chao ${ }^{2} \cdot$ Yanping $\mathrm{Miao}^{3} \cdot \mathrm{Jun}_{\mathrm{Li}^{3}} \cdot$ \\ Fei $\mathrm{Chen}^{4}$
}

Received: 14 March 2019/Revised: 20 September 2019/Accepted: 9 October 2019/Published online: 12 November 2019

(C) The Author(s) 2019

\begin{abstract}
Two case studies were conducted in the Shennan mining area of Shaanxi Province, China to evaluate the surrounding rock deformation and stress evolution in pre-driven longwall recovery rooms. These studies mainly monitored the surrounding rock deformation and coal pillar stress in the recovery rooms of the N1206 panel of $2^{-2}$ coal seam at Ningtiaota Coal Mine and the 15205 panel of $5^{-2}$ coal seam at Hongliulin Coal Mine. The monitoring results showed that the surrounding rock deformation of the main recovery room and the coal pillar stress in the N1206 and 15205 panels began to increase significantly when the face was $36 \mathrm{~m}$ and $42 \mathrm{~m}$ away from the terminal line, respectively. After the face entered the main recovery room, the maximum roof-to-floor convergence in the N1206 and 15205 panels was $348.03 \mathrm{~mm}$ and $771.24 \mathrm{~mm}$, respectively, and the coal pillar stresses increased more than $5 \mathrm{MPa}$ and $7 \mathrm{MPa}$, respectively. In addition, analysis of the periodic weighting data showed that the main roof break position of the N1206 and 15205 panels after the longwall face entered the main recovery room was $-3.8 \mathrm{~m}$ and $-8.2 \mathrm{~m}$, respectively. This research shows that when the main roof breaks above the coal pillar, the surrounding rock deformation of the main recovery room and the coal pillar stress increase sharply. The last weighting is the key factor affecting the stability of the main recovery room and the coal pillar; main roof breaks at disadvantageous positions are the main cause of the support crushing accidents.
\end{abstract}

Keywords Pre-driven longwall recovery room $\cdot$ Surrounding rock deformation $\cdot$ Stress evolution $\cdot$ Periodic weighting

\section{Introduction}

Moving equipment is crucial in longwall coal mining practices, and the speed at which the equipment can be moved affects the mining efficiency. The moving method

Bonan Wang

wangbonan@xaut.edu.cn

1 School of Civil Engineering and Architecture, Xi'an University of Technology, Xi' an 710048, Shaanxi, People's Republic of China

2 Shennan Hongliulin Mining Co Ltd of Shaanxi Coal Group, Shenmu 719300, Shaanxi, People's Republic of China

3 Shennan Zhangjiamao Mining Co Ltd of Shaanxi Coal Group, Shenmu 719300, Shaanxi, People's Republic of China

4 Shennan Ningtiaota Mining Co Ltd of Shaanxi Coal Group, Shenmu 719300, Shaanxi, People's Republic of China adopted by most coal mines in China is the pre-driven double recovery room. This room drives two roadways parallel to the longwall face along the terminal line. The longwall equipment is transported to the headgate or tailgate via the recovery room and is then moved to the main haulage roadway and the next panel. If the surrounding rock deformation of the recovery room is too large, the normal operation of all subsequent processes will be affected during the moving stage. Therefore, the surrounding rock stability of the recovery room is the key factor that affects how quickly the equipment can be moved.

A number of studies have been conducted in relation to pre-driven longwall recovery rooms. From the late 1980s to the 1990s, certain researchers studied the surrounding rock stability in recovery rooms and summarized the numerous cases of roof fall hazards and the effects of front abutment pressure on supports (Listak and Bauer 1989; Oyler et al. 
1998). In the twentieth century, the support technology in recovery rooms improved with the maturity of highstrength support technology. Tadolini et al. (2003) and Tadolini and Barczak $(2006,2008)$ had designed the support system of pre-driven recovery rooms, which consists of bolts, cables, and standing supports, such as pumpable supports, timbers, and concrete cribs, and studied the behavior of rock mass and support response in recovery rooms. By evaluating the mechanics of support load transfer and ground response associated with the advancement of the longwall face into recovery rooms, additional design methods of support parameters have been proposed and advanced (Tadolini 2003; Barczak et al. 2007; Barczak and Tadolini 2008; Kang et al. 2016).

In previous studies, almost all coal mines have used concrete cribs to support the recovery room. In recent years, certain coal mines in China have used buttress hydraulic support instead of concrete cribs to reinforce the roof in recovery rooms. Compared with concrete cribs, buttress hydraulic supports require quick installation and are reusable. At present, the support technology of predriven recovery rooms in China is mature, but roof fall hazards still occur frequently. Between 2010 and 2013, numerous roof fall hazards and support-crushing accidents occurred in the Shennan mining area, Shaanxi Province, China. For example, the roof-to-floor convergence reached $1.2 \mathrm{~m}$ in the recovery room of N14201 longwall panel at the Zhangjiamao Coal Mine and resulted in most of the hydraulic supports in the recovery room being crushed, which seriously affected the production efficiency of the coal mines. Similar accidents have shown that the mechanism of large surrounding rock deformation in recovery rooms is still not well understood. Thus, researchers have focused on the mechanism of surrounding rock instability in the recovery room. Wichlacz et al. (2009) have analyzed the main parameters that impact the successful implementation of the recovery room and developed a program to evaluate longwall recovery operations. Lv (2014) has discussed the key factors that affect the stability of predriven recovery rooms and offered a mechanical model of the unmined coal pillar. $\mathrm{Gu}$ et al. (2015) has studied the load transfer mechanical mechanism of the unmined coal pillar and the coal pillar during the end of the mining stage based on theoretical analysis, derived load calculation formulas of the coal pillar, and proposed a method to determine the width of the coal pillar. Shu et al. (2018) has adopted numerical simulation and theoretical analysis to study the influence of buried depth on roof fall and rib sliding in recovery rooms. However, contrastive studies have not been conducted on the surrounding rock deformation and stress distribution in the recovery rooms of different coal seams, and few studies have been conducted on combining periodic weighting and surrounding rock deformation.

This study mainly evaluated the surrounding rock deformation, coal pillar stress evolution, and periodic weighting in the pre-driven longwall recovery rooms of two different coal seams at the Ningtiaota Coal Mine (N1206 panel of $2^{-2}$ coal seam) and the Hongliulin Coal Mine (15205 panel of $5^{-2}$ coal seam). This study compared the surrounding rock deformation and coal pillar stress monitoring data of the recovery room in the two panels. Based on the monitoring data, the periodic weighting data were analyzed, and the main roof break positions of the two panels were determined. From the results of the study, the key factor affecting the surrounding rock deformation and coal pillar stress distribution in the recovery rooms were determined.

\section{General conditions}

\subsection{Roof and coal seam conditions}

Table 1 lists the roof lithology and occurrence conditions of the $2^{-2}$ and $5^{-2}$ coal seams. The average thicknesses of the $2^{-2}$ and $5^{-2}$ coal seams are $5.46 \mathrm{~m}$ and $7.23 \mathrm{~m}$, respectively, thus being classified as thick coal seams. The immediate and main roofs of the two coal seams are mainly composed of sandstone with high strength and large thickness. The buried depth of the two coal seams is basically no more than $200 \mathrm{~m}$. The roof condition in the Shennan mining area has favorable stability, which is easy to maintain and usually does not cause large deformation and collapse.

\subsection{Support and mining conditions}

The N1206 and 15205 panels use pre-driven double recovery rooms. The pattern of the supports in the main recovery rooms of the two panels was shown in Table 2. The recovery room of each coal mine adopts the support method of bolts, cables, and hydraulic supports. Initial supports include bolts and cables; two rows of buttress hydraulic supports have been installed as reinforcement support before the longwall face enters the main recovery room.

The support parameters and mining conditions of the two panels are shown in Table 3. The length of the recovery room of the two panels was $300 \mathrm{~m}$, and the section dimensions were basically the same. The width of the coal pillar in the N1206 and 15205 panels was $20 \mathrm{~m}$. The yield loads of buttress hydraulic supports in the N1206 and 15205 panels were $12000 \mathrm{kN}$ and $18000 \mathrm{kN}$, respectively. 
Table 1 Lithology and roof condition of $2^{-2}$ and $5^{-2}$ coal seams

\begin{tabular}{|c|c|c|c|c|c|c|}
\hline \multirow{2}{*}{$\begin{array}{l}\text { Coal seam } \\
\text { number }\end{array}$} & \multirow{2}{*}{$\begin{array}{l}\text { Coal seam average thickness } \\
\text { (m) }\end{array}$} & \multicolumn{2}{|c|}{ Immediate roof } & \multicolumn{2}{|l|}{ Main roof } & \multirow{2}{*}{$\begin{array}{l}\text { Depth range } \\
(\mathrm{m})\end{array}$} \\
\hline & & Lithology & $\begin{array}{l}\text { Average thickness } \\
\text { (m) }\end{array}$ & Lithology & $\begin{array}{l}\text { Average thickness } \\
\text { (m) }\end{array}$ & \\
\hline $2^{-2}$ & 5.46 & Siltstone & 6.84 & Fine sandstone & 14.40 & 83-205 \\
\hline $5^{-2}$ & 7.23 & Sandstone & 7.50 & $\begin{array}{l}\text { Medium } \\
\text { sandstone }\end{array}$ & 19.27 & $23-206$ \\
\hline
\end{tabular}

Table 2 Pattern of supports in the main recovery room of $2^{-2}$ and $5^{-2}$ coal seams

\begin{tabular}{lllll}
\hline Longwall panels & Type of layout & Support pattern (main recovery room) & \\
\cline { 3 - 5 } & & Roof & Coal pillar rib & Mining rib \\
\hline N1206 & Pre-driven double recovery room & Steel bolts, cables, and buttress hydraulic supports & Steel bolts & - \\
15205 & Pre-driven double recovery room & Steel bolts, cables, and buttress hydraulic supports & Steel bolts & FRP bolts \\
\hline
\end{tabular}

Table 3 Support parameters and mining conditions of the N1206 and 15205 panels

\begin{tabular}{|c|c|c|c|c|c|c|c|}
\hline \multirow{2}{*}{$\begin{array}{l}\text { Longwall } \\
\text { panels }\end{array}$} & \multirow{2}{*}{$\begin{array}{l}\text { Buried depth } \\
\text { (m) }\end{array}$} & \multicolumn{2}{|c|}{ Longwall face } & \multicolumn{4}{|c|}{ Main recovery room } \\
\hline & & $\begin{array}{l}\text { Mining } \\
\text { height (m) }\end{array}$ & $\begin{array}{l}\text { Chock-shield supports yield } \\
\text { load }(\mathrm{kN})\end{array}$ & $\begin{array}{l}\text { Height } \\
(\mathrm{m})\end{array}$ & $\begin{array}{l}\text { Width } \\
(\mathrm{m})\end{array}$ & $\begin{array}{l}\text { Buttress supports yield } \\
\text { load }(\mathrm{kN})\end{array}$ & $\begin{array}{l}\text { Coal pillar } \\
\text { width }(\mathrm{m})\end{array}$ \\
\hline N1206 & 182 & 5.5 & 12000 & 4.45 & 5.9 & 12000 & 20 \\
\hline 15205 & 198 & 6.7 & 17000 & 4.5 & 6.0 & 18000 & 20 \\
\hline
\end{tabular}

\section{Field monitoring instrument}

Field monitoring contents include surrounding rock deformation, coal pillar stress, and canopy-to-base convergence of buttress hydraulic supports. All instruments were installed before the longwall face was $100-150 \mathrm{~m}$ away from the recovery room.

The main monitoring instruments were as follows:

(1) Displacement meters were used to measure roof-tofloor and coal pillar rib convergence.

(2) Laser rangefinders were used to measure canopy-tobase convergence of the buttress hydraulic supports.

(3) Borehole pressure cells were installed in the coal pillar rib to measure stress changes, and the installation depths were $1 \mathrm{~m}, 2 \mathrm{~m}, 3 \mathrm{~m}, 4 \mathrm{~m}, 6 \mathrm{~m}$, and $8 \mathrm{~m}$.

The layout of the monitoring stations is shown in Fig. 1. Five surrounding rock deformation monitoring stations and two coal pillar stress monitoring stations were established. Stations 2, 3 and 4, which monitor the surrounding rock deformation and the two stress monitoring stations were located within the range of 100-200 $\mathrm{m}$ in the middle of the recovery room. Stations 1 and 5, which also monitor the surrounding rock deformation, were located at $50 \mathrm{~m}$ from the opposite ends of the recovery room.

\section{Monitoring results and analysis}

\subsection{Roof-to-floor convergence}

The roof-to-floor convergence monitoring data of the two panels are shown in Fig. 2 and Table 4. In accordance with the monitoring data, the variation of the roof-to-floor convergence of a recovery room can be divided into four stages:

Stage 1 (stable stage) The recovery room is far from the longwall face and is rarely affected by mining advance; the change of the roof-to-floor convergence is very small at this stage.

Stage 2 (increasing stage) When the longwall face is mined at a certain distance away from the terminal line, it enters into Stage 2. Began within Stage 2, the surrounding rock of the recovery room is gradually damaged, and the roof-to-floor convergence begins to increase significantly. The longwall face will gradually begin to reduce the mining height to the height of the main recovery room. The 


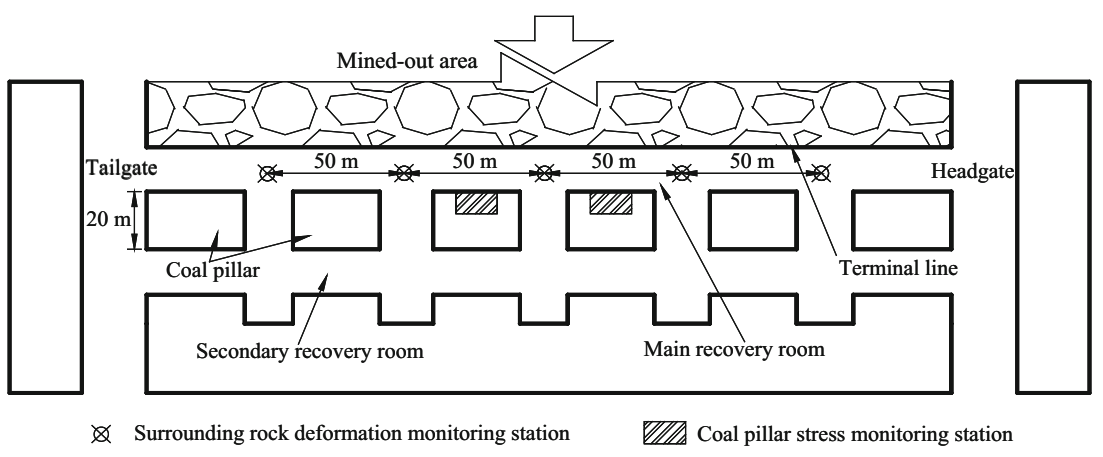

Fig. 1 Layout of monitoring stations in the recovery room

(a)

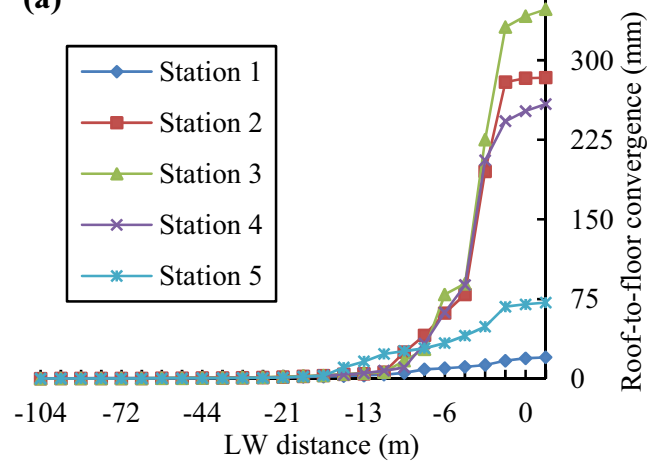

(b)

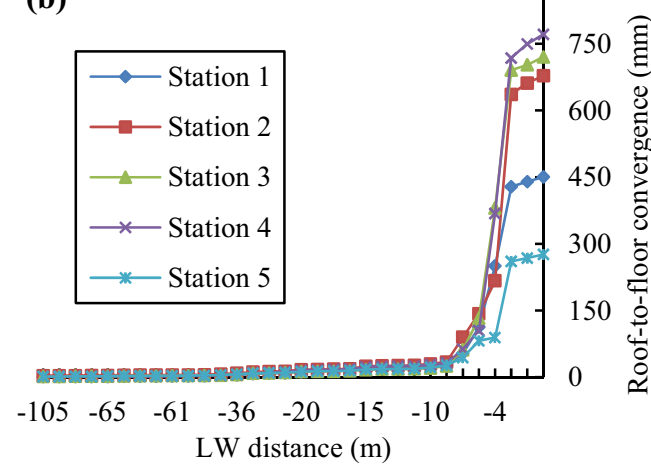

Fig. 2 Roof-to-floor convergence of the main recovery room: a N1206 panel and b 15205 panel

starting distances of the N1206 and 15205 panels to reduce the mining height were $15 \mathrm{~m}$ and $20 \mathrm{~m}$, respectively.

Stage 3 (peak stage) From this stage, the longwall face is about to enter the main recovery room. The roof-to-floor convergence increases sharply, and the convergence rate reaches its peak value when the face enters the main recovery room.

Stage 4 (decreasing stage) At this stage, the longwall face has entered the main recovery room, but the movement of the equipment has not started yet. Mining stopped, and the roof-to-floor convergence rate decreased as the convergence deformation continued.
Figure 2 and Table 4 show that the initial distance and the roof-to-floor convergence of the two panels at each stage were different. The initial distance affected by mining in each panel was $36 \mathrm{~m}$ (N1206 panel) and $42 \mathrm{~m}$ (15205 panel). The maximum roof-to-floor convergence in the main recovery room of each panel was $348.03 \mathrm{~mm}$ (N1206 panel) and $771.24 \mathrm{~mm}$ (15205 panel). Starting from Stage 3, the convergence data of Stations 2, 3, and 4 began to increase considerably compared with those of Stations 1 and 5. This increase was caused by the fact that the opposite ends of the main recovery room were close to the headgate and tailgate, and certain parts of the abutment pressure were carried by the unmined coal pillar.

Although the basic variation of the roof-to-floor convergence of the main recovery room in the two panels is consistent, the roof-to-floor convergence of the main recovery room in the 15205 panel was larger than that in the N1206 panel. The initial distance affected by mining in the 15205 panel was farther than that in the N1206 panel, which indicates that the higher the mining height, the more evident the influence of mining on the recovery room is.

\subsection{Coal pillar rib convergence}

The coal pillar rib convergence monitoring data of the two panels are shown in Fig. 3 and Table 5. The monitoring data showed that the change rule of coal pillar rib convergence in the N1206 and 15205 panels were basically the same as that of roof-to-floor convergence. The maximum coal pillar rib convergence of the main recovery room in each panel was $177.36 \mathrm{~mm}$ (N1206 panel) and $232.76 \mathrm{~mm}$ (15205 panel). After entering Stage 3, the coal pillar rib convergence in Stations 2, 3, and 4 began to increase rapidly, and the coal pillar began to show spalling damage. In the N1206 panel, the coal pillar rib convergence in the middle of the main recovery room could be 20 times larger at the opposite ends when the longwall face entered into the main recovery room. In the 15205 panel, the coal pillar rib convergence was less than $40 \%$ of the roof-to-floor convergence. However, given that certain parts of the recovery 
Table 4 Maximum roof-to-floor convergence of the main recovery room at each stage

\begin{tabular}{|c|c|c|c|c|c|c|c|c|}
\hline \multirow{2}{*}{$\begin{array}{l}\text { Longwall panel } \\
\text { Stage }\end{array}$} & \multicolumn{4}{|c|}{ N1206 } & \multicolumn{4}{|l|}{15205} \\
\hline & 1 & 2 & 3 & 4 & 1 & 2 & 3 & 4 \\
\hline Longwall distance $(\mathrm{m})$ & $>36$ & $36-10$ & $10-0$ & 0 & $>42$ & $42-8$ & $8-0$ & 0 \\
\hline \multicolumn{9}{|c|}{ Maximum convergence (mm) } \\
\hline Station 1 & 0.92 & 5.34 & 16.78 & 20.00 & 4.30 & 26.93 & 428.54 & 450.45 \\
\hline Station 2 & 0.57 & 24.97 & 279.44 & 283.05 & 6.75 & 33.94 & 636.28 & 678.23 \\
\hline Station 3 & 0.72 & 16.77 & 331.24 & 348.03 & 4.63 & 25.17 & 690.86 & 720.63 \\
\hline Station 4 & 0.42 & 10.57 & 242.59 & 258.68 & 4.03 & 31.70 & 717.98 & 771.24 \\
\hline Station 5 & 0.32 & 25.95 & 67.64 & 71.52 & 4.87 & 26.38 & 260.56 & 276.14 \\
\hline
\end{tabular}

room were spalled seriously, the actual deformation of coal pillar rib in the 15205 panel was larger than the monitoring data.

\subsection{Canopy-to-base convergence of buttress hydraulic supports}

The canopy-to-base convergence of the buttress hydraulic supports is shown in Fig. 4. The monitoring results showed that the canopy-to-base convergence between the two rows of buttress hydraulic supports was different. The canopy-to-base convergence of the buttress hydraulic supports on the side of the mining rib was larger than that on the side of the coal pillar rib, which means that the roof deformation form of the main recovery room is tilting and sinking.

The canopy-to-base convergence data of buttress hydraulic supports in each panel are shown in Table 6. In the N1206 panel, the canopy-to-base convergence of buttress hydraulic supports in the middle was 12-19 times larger than that at the opposite ends, whereas the same convergence was 13-24 times in the 15205 panel. The difference in the canopy-to-base convergence between the two rows of buttress hydraulic supports in the middle of the recovery room was $70.12 \mathrm{~mm}$ (N1206 panel) and $190.8 \mathrm{~mm}$ (15205 panel). The convergence at the opposite ends of the main recovery room does not change much but increases sharply within the range of $150-200 \mathrm{~m}$ in the middle. In addition, the roof's tendency to tilt and sink is evident.

\subsection{Vertical stress change in coal pillar}

Figure 5 shows the vertical stress change in the coal pillar of each panel. In accordance with Fig. 5, we determine that the vertical stress change rule in the coal pillar is basically consistent with the change rule of the surrounding rock deformation. When the surrounding rock is significantly

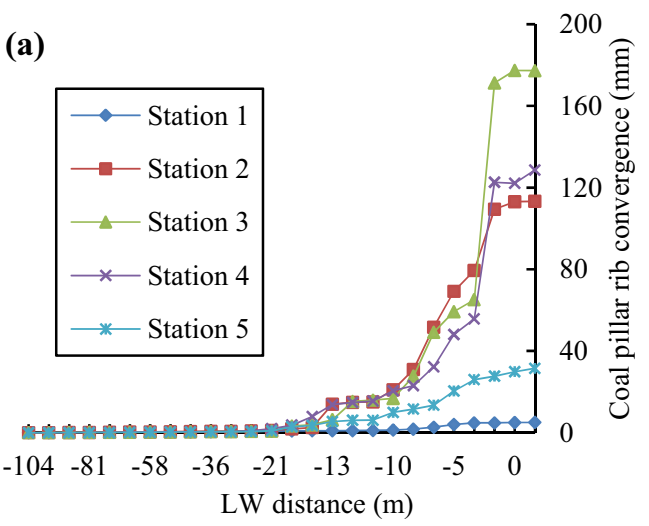

(b)

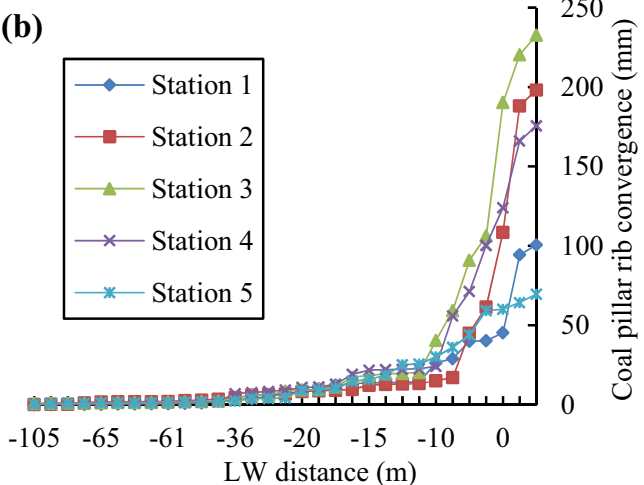

Fig. 3 Coal pillar rib convergence of the main recovery room: a N1206 panel and b 15205 panel

deformed, the vertical stress of coal pillar begins to increase. The coal pillar stress in the N1206 and 15205 panels has increased significantly by more than $5 \mathrm{MPa}$ and $7 \mathrm{MPa}$, respectively. Given that the stress monitoring stations were all arranged in the middle of the recovery rooms, the average stress changes of the stations in each panel are not much different. In the few shallow stress monitoring points, the stress is reduced in the end due to the serious damage of the coal pillar after the face has entered the recovery room. 
Table 5 Maximum coal pillar rib convergence of the main recovery room at each stage

\begin{tabular}{|c|c|c|c|c|c|c|c|c|}
\hline \multirow{2}{*}{$\begin{array}{l}\text { Longwall panel } \\
\text { Stage }\end{array}$} & \multicolumn{4}{|c|}{ N1206 } & \multicolumn{4}{|l|}{15205} \\
\hline & 1 & 2 & 3 & 4 & 1 & 2 & 3 & 4 \\
\hline Distance (m) & $>36$ & $36-10$ & $10-0$ & 0 & $>42$ & $42-8$ & $8-0$ & 0 \\
\hline \multicolumn{9}{|c|}{ Maximum convergence $(\mathrm{mm})$} \\
\hline Station 1 & 0.42 & 1.24 & 4.78 & 5.05 & 2.13 & 28.93 & 45.23 & 100.58 \\
\hline Station 2 & 0.67 & 20.98 & 109.44 & 113.26 & 3.38 & 16.97 & 108.47 & 198.15 \\
\hline Station 3 & 0.52 & 16.77 & 171.24 & 177.36 & 2.32 & 59.29 & 190.28 & 232.76 \\
\hline Station 4 & 0.52 & 20.57 & 122.59 & 128.68 & 2.02 & 55.85 & 124.02 & 175.61 \\
\hline Station 5 & 0.42 & 9.95 & 27.64 & 31.52 & 1.87 & 36.12 & 60.01 & 69.54 \\
\hline
\end{tabular}
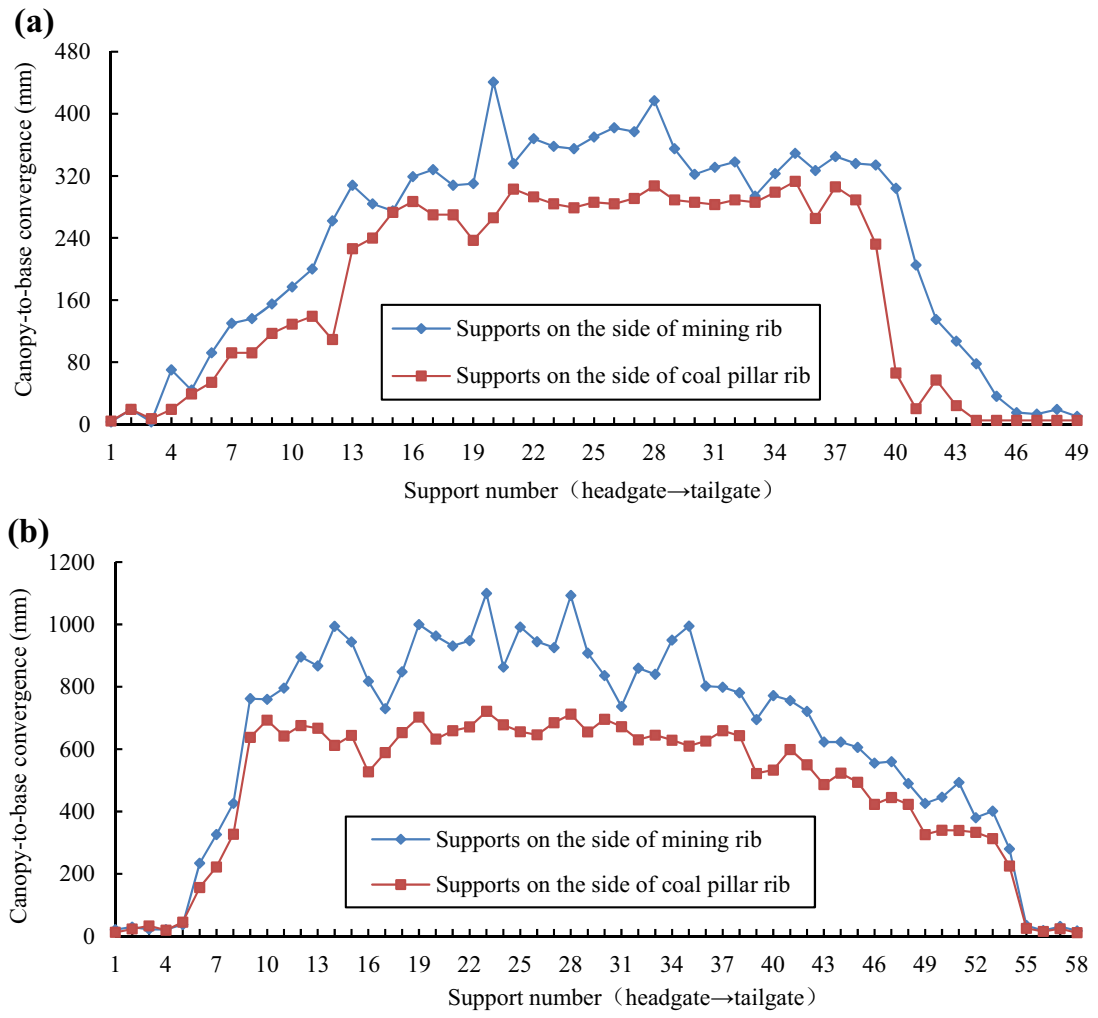

Fig. 4 Canopy-to-base convergence of buttress hydraulic supports: a N1206 panel and b 15205 panel

Table 6 Canopy-to-base convergence of buttress hydraulic supports in the main recovery room

\begin{tabular}{|c|c|c|c|c|c|c|}
\hline \multirow{2}{*}{$\begin{array}{l}\text { Longwall panel } \\
\text { Average canopy-to-base convergence of } \\
\text { supports }\end{array}$} & \multicolumn{3}{|l|}{ N1206 } & \multicolumn{3}{|l|}{15205} \\
\hline & $\begin{array}{l}\text { Mining rib } \\
(\mathrm{mm})\end{array}$ & $\begin{array}{l}\text { Coal pillar rib } \\
(\mathrm{mm})\end{array}$ & $\begin{array}{l}\text { Difference } \\
(\mathrm{mm})\end{array}$ & $\begin{array}{l}\text { Mining rib } \\
(\mathrm{mm})\end{array}$ & $\begin{array}{l}\text { Coal pillar rib } \\
(\mathrm{mm})\end{array}$ & $\begin{array}{l}\text { Difference } \\
(\mathrm{mm})\end{array}$ \\
\hline Opposite ends & 23.20 & 11.30 & 11.90 & 31.11 & 23.00 & 8.11 \\
\hline Middle & 286.45 & 216.33 & 70.12 & 744.84 & 554.04 & 190.80 \\
\hline
\end{tabular}




\section{Discussions}

Figure 6 shows the comparison of surrounding rock deformation in the recovery room of the N1206 and 15205 panels. The buried depths of the $2^{-2}$ and $5^{-2}$ coal seams were both close to $200 \mathrm{~m}$, and the mining heights were $5.5 \mathrm{~m}$ and $6.7 \mathrm{~m}$. The roof and mining conditions of the two panels are similar. However, the difference of the surrounding rock deformation in the main recovery room between the two panels is close to $500 \mathrm{~mm}$. Combined with Fig. 2, after the 15205 panel entered the main recovery room, the roof-to-floor convergence has increased larger than that in the N1206 panel. This increase indicates that the roof of the 15205 panel was unstable after the face entered the main recovery room. This situation will affect the movement of equipment and supports. Given the excessive surrounding rock deformation of the main recovery room in the 15205 panel, the pillar strokes of buttress hydraulic supports in the middle were pressed too small, which makes movement difficult.

Figure 7 shows the vertical stress distribution in the coal pillar after the longwall face entered the main recovery
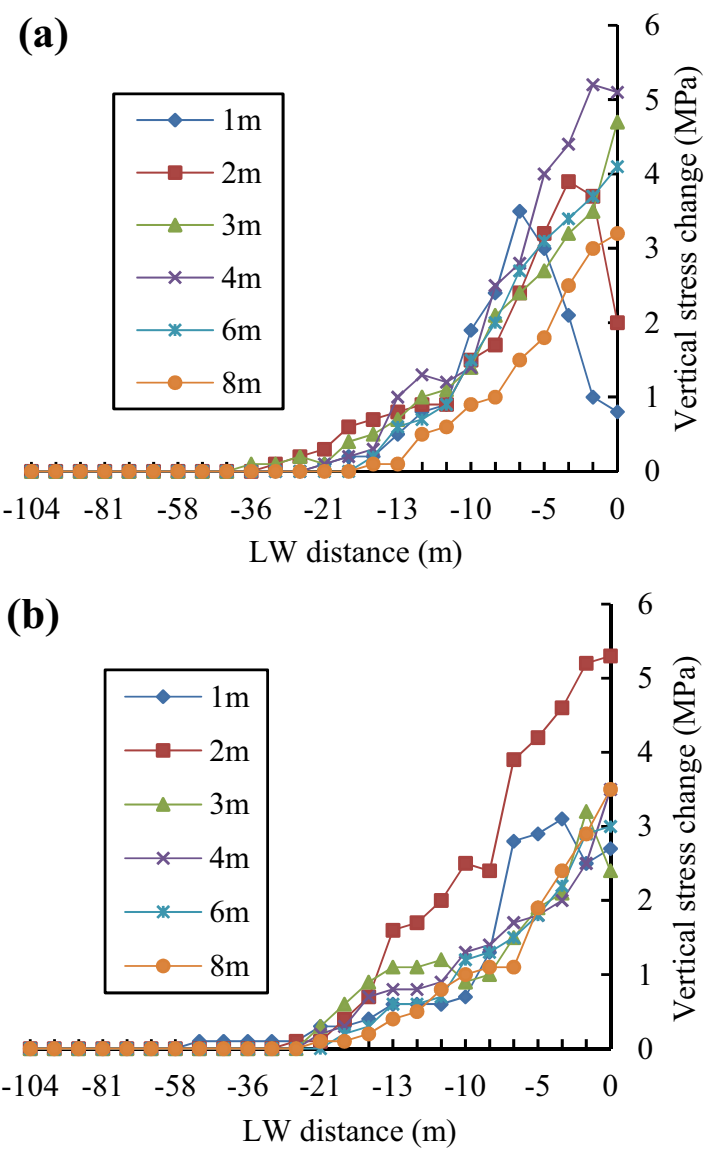

room. The peak stress position in the coal pillar of the $\mathrm{N} 1206$ panel is $4 \mathrm{~m}$. However, the overall stress of the coal pillar in the 15205 panel was larger, and the peak stress position has reached $6 \mathrm{~m}$. This result indicates that the excessive surrounding rock deformation in the 15205 panel has increased the overall stress of the coal pillar, which has also widened the plastic zone. In this scenario, the coal pillar is likely to lose stability and to be damaged in the process of moving, which is adverse to maintain the surrounding rock stability.

The large deformation of the surrounding rock of the main recovery room in the 15205 panel shows that the roof movement may be significant under certain circumstances after the longwall face enters the recovery room. Barczak et al. (2007) and Tadolini and Barczak (2008) have confirmed that the recovery room is significantly affected by the periodic weighting. Therefore, to determine the primary cause of the large deformation of surrounding rock in the recovery room, periodic weighting should be analyzed during the end of the mining stage.

(c)

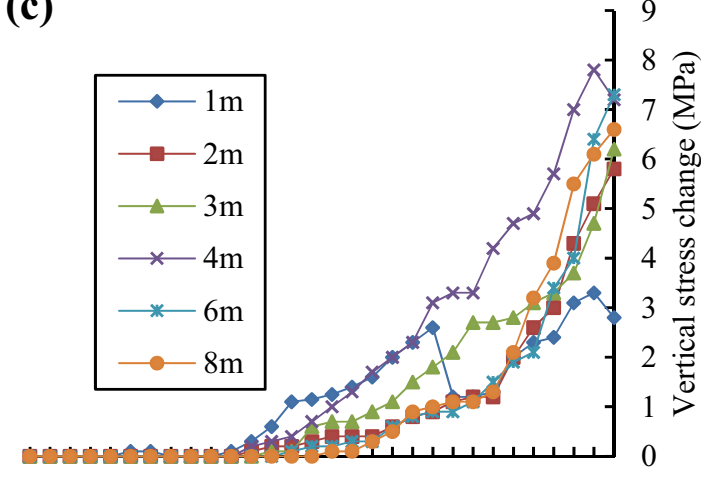

$\begin{array}{llllllllll}-105 & -71 & -62 & -58 & -36 & -22 & -18 & -14 & -10 & -5\end{array}$

LW distance (m)

(d)

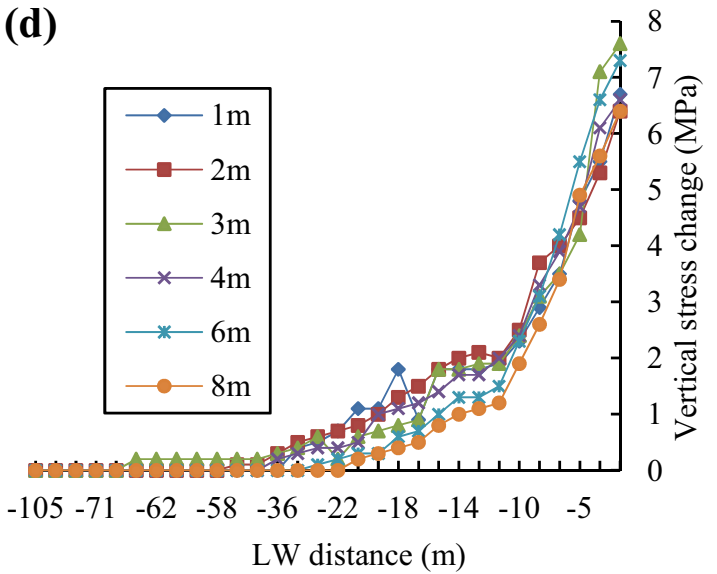

Fig. 5 Vertical stress changes in the coal pillar of the recovery room: a Station 1 in the N1206 panel, b Station 2 in the N1206 panel, c Station 1 in the 15205 panel, and d Station 2 in the 15205 panel 


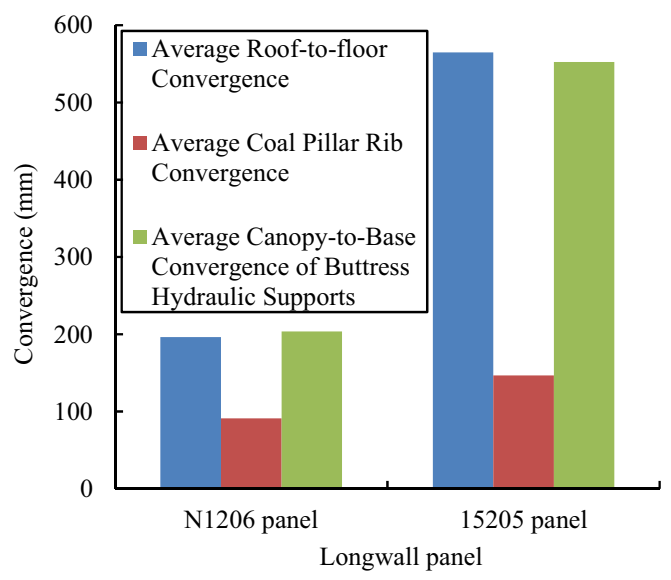

Fig. 6 Comparison of surrounding rock deformation of the main recovery room in the two panels

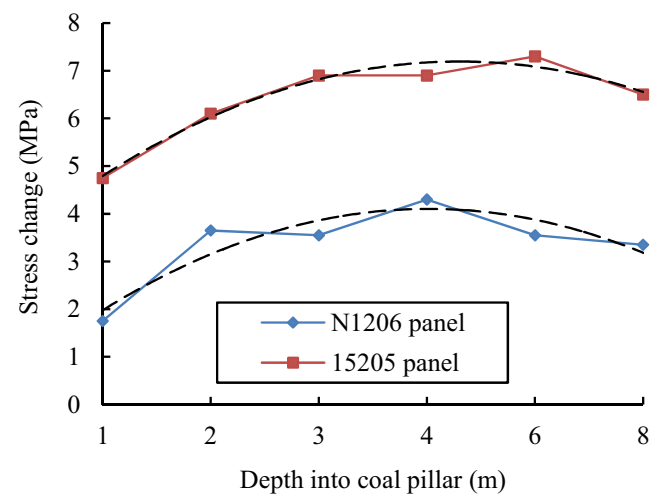

Fig. 7 Stress distribution in the coal pillar after face entered the main recovery room

\section{Analysis of periodic weighting}

In accordance with strata behavior observations in the mining practices of China, when the longwall face enters the recovery room, the main roof may continue to break and collapse. Based on the different break positions of the main roof after the longwall face enters the main recovery room, the main roof failure form can be divided into three types (Wang et al. 2012a, b), as shown in Fig. 8. Among the three forms of main roof failure, the third form is the most unstable. In Fig. 8c, when the main roof breaks above the coal pillar, the entire main recovery room is under the influence of the rock mass rotation. With the movement of supports, Rock Mass B will rotate around the coal pillar as its fulcrum. As a result, the coal pillar is further compressed and damaged, and the surrounding rock deformation of the main recovery room increases continuously. Compared with the third failure form, when the main roof breaks above the main recovery room, the surrounding rock deformation of the main recovery room will grow larger. However, the difference is that the coal pillar is less affected in this condition. Thus, the surrounding rock stability of the main and secondary recovery rooms can still be maintained.

The break position of the main roof is calculated based on the main roof periodic weighting positions and steps data. Table 7 shows the positions and steps of the periodic weightings at the end of the mining stage, which is obtained from the real-time observation system of the N1206 and 15205 panels. Before the longwall face entered the main recovery room, 10 and 11 periodic weightings have occurred in the N1206 and 15205 panels, respectively. The average periodic weighting steps of the N1206 and 15205 panels at the end of the mining stage were $17.3 \mathrm{~m}$ and $19.7 \mathrm{~m}$, respectively, and the periodic weighting position before the face enters the main recovery room were located $13.5 \mathrm{~m}$ and $11.5 \mathrm{~m}$ in front of the terminal line, respectively. To calculate the break position of the main roof after the longwall face enters the main recovery room, three factors must be clarified, including the periodic weighting position, the last weighting step when the longwall face enters the main recovery room, and whether the last weighting occurs after the longwall face enters the main recovery room. If the periodic weighting occurs after the longwall face enters the main recovery room, the main roof break position can be determined by:

$d=s-l$.

If the periodic weighting does not occur after the longwall face enters the main recovery room, the main roof break position can be determined by:

$d=s$

where $d$ is the main roof break position after the longwall face enters the main recovery room $(m), s$ is the periodic weighting position before the longwall face enters the main recovery room $(m)$, and $l$ is the last weighting step $(m)$. Given that mining stops after the longwall face enters the main recovery room, $l$ cannot be accurately determined by the observation system, and we can take the average value of the periodic weighting steps as $l$.

In Eq. (1), the last weighting step $l$ is generally larger than the longwall distance $s$, thus, the main roof break position $d$ will be negative, which means the break position is behind the terminal line. Correspondingly, Eq. (2) means the main roof break position is in front of the terminal line. The periodic weighting real-time observation system of the two panels shows that the periodic weighting occurs in the N1206 and 15205 panels after the face enters the main recovery room. Therefore, according to the data in Table 7 and Eq. (1), the main roof break position of each panel after the face enters the main recovery room is - $3.8 \mathrm{~m}$ (N1206 panel) and - $8.2 \mathrm{~m}$ (15205 panel). The calculation results show that the main roof break position 


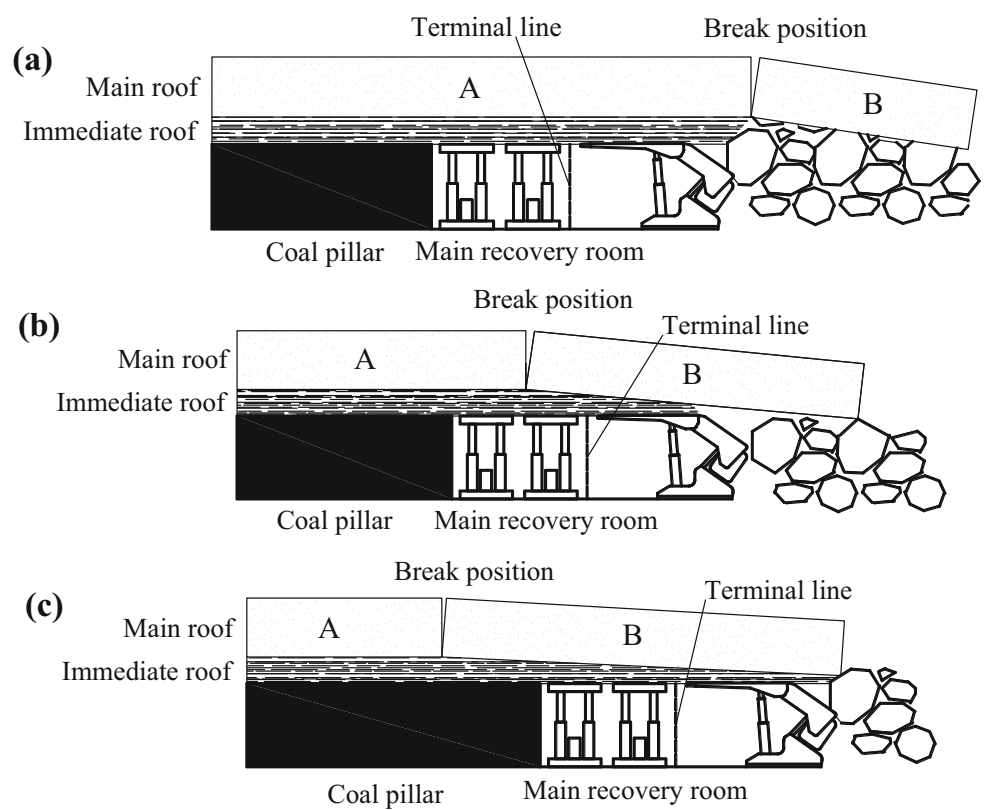

Fig. 8 Forms of main roof failure after the longwall face enters the main recovery room: a The main roof breaks behind the shield hydraulic supports, $\mathbf{b}$ the main roof breaks above the main recovery room and supports, and $\mathbf{c}$ the main roof breaks above the coal pillar

Table 7 Periodic pressure positions and steps of each panel before the longwall face enters the main recovery room

\begin{tabular}{|c|c|c|c|c|}
\hline \multirow{2}{*}{$\begin{array}{l}\text { Longwall panel } \\
\text { Number of periodic weighting }\end{array}$} & \multicolumn{2}{|l|}{ N1206 } & \multicolumn{2}{|l|}{15205} \\
\hline & Position (m) & Step (m) & Position (m) & Step (m) \\
\hline 1 & 169 & - & 208 & - \\
\hline 2 & 149 & 20 & 189.5 & 18.5 \\
\hline 3 & 131 & 18 & 169.5 & 20 \\
\hline 4 & 116.5 & 14.5 & 150 & 19.5 \\
\hline 5 & 98.5 & 18 & 131 & 19 \\
\hline 6 & 77 & 21.5 & 110 & 21 \\
\hline 7 & 61.5 & 15.5 & 91.5 & 18.5 \\
\hline 8 & 45.5 & 16 & 72 & 19.5 \\
\hline 9 & 28.5 & 17 & 53 & 19 \\
\hline 10 & 13.5 & 15 & 34 & 19 \\
\hline 11 & - & - & 11.5 & 22.5 \\
\hline Average & - & 17.3 & - & 19.7 \\
\hline
\end{tabular}

in the N1206 panel is above the main recovery room, and the main roof breaks above the coal pillar in the 15205 panel.

An important reason for the large deformation of the surrounding rock in the recovery room of the 15205 panel is that the main roof breaks above the coal pillar after the longwall face enters the main recovery room. In this situation, the maintenance of the roof stability remains difficult even if the high-strength buttress hydraulic supports have been used in the 15205 panel, which has caused the damage of the coal pillars and the hydraulic support crushing accident. To avoid such cases of failure, the last weighting step should be adjusted artificially to reduce the roof pressure, such as caving the roof and yield mining.

\section{Conclusions}

This paper presented two case studies to evaluate the surrounding rock deformation and stress evolution in the predriven longwall recovery rooms of the N1206 panel of $2^{-2}$ coal seam at the Ningtiaota Coal Mine and the 15205 panel of $5^{-2}$ coal seam at the Hongliulin Coal Mine. The surrounding rock deformation and the coal pillar stress 
monitoring were performed in the two panels to grasp the surrounding rock deformation and stress changes of the recovery rooms as the longwall face approached and entered the recovery rooms. By analyzing the periodic weighting of the two panels, the main roof break positions of the two panels were determined. Based on the monitoring data, the following main conclusions were obtained:

(1) The influence of the front abutment pressure on the recovery room could be divided into four stages. The initial distances of the increasing stage in the N1206 and 15205 panels were $36 \mathrm{~m}$ and $42 \mathrm{~m}$, respectively. The initial distance affected by mining advanced with the increase of the mining height. When the longwall face was approximately $8-10 \mathrm{~m}$ away from the terminal line, the surrounding rock deformation of the main recovery room and the coal pillar stress began to increase sharply. The roof's large deformation and the rib spalling failure mainly occurred before the face entered the main recovery room.

(2) The maximum roof-to-floor convergences of the main recovery room in the N1206 and 15205 panels were 348.03 and $771.24 \mathrm{~mm}$, respectively, and the coal pillar stress increased by more than $5 \mathrm{MPa}$ and $7 \mathrm{MPa}$, respectively. The surrounding rock deformation in the middle of the main recovery rooms was much larger than that at the opposite ends, and the roof deformation form of the main recovery rooms was tilting and sinking. When designing the support parameters, the uneven deformation rule of the main recovery room should be considered. The strength and density of the supports in the middle of the main recovery room should be higher than that at the opposite ends.

(3) The main roof break position after the face entered the main recovery room of the two panels was determined based on the periodic weighting data. The main roof break positions of the N1206 and 15205 panels were $3.8 \mathrm{~m}$ and $8.2 \mathrm{~m}$ behind the terminal line, respectively. The main roof's last weighting is the key factor affecting the stability of the main recovery room and the coal pillar. When the main roof broke above the coal pillar, the surrounding rock deformation of the main recovery room and the coal pillar stress increased sharply and caused the hydraulic support crushing accident.

\footnotetext{
Acknowledgements Support for this work was provided by the National Natural Science Foundation of China (No. 51679199), Key Laboratory for Science and Technology Co-ordination and Innovation Projects of Shaanxi Province (No. 2014SZS15-Z01) and is thankfully acknowledged by the authors.
}

\section{Compliance with ethical standards}

Conflict of interest The authors declare that they have no conflict of interest.

Open Access This article is distributed under the terms of the Creative Commons Attribution 4.0 International License (http://crea tivecommons.org/licenses/by/4.0/), which permits unrestricted use, distribution, and reproduction in any medium, provided you give appropriate credit to the original author(s) and the source, provide a link to the Creative Commons license, and indicate if changes were made.

\section{References}

Barczak TM, Tadolini SC (2008) Pumpable roof supports: an evolution in longwall roof support technology. Trans Soc Min Met Explor 324:19-31

Barczak TM, Tadolini SC, Zhang P (2007) Evaluation of support and ground response as longwall face advances into and widens pre-driven recovery room. In: Proceedings of the 26th international conference ground control min. Morgantown, WV, pp $160-172$

Gu SC, Wang BN, Huang RB, Miao YP (2015) Method for determining coal pillar load and width in retracement channel at ending stage of fully-mechanized face. J China Univ Min Technol 6:990-995 (in Chinese)

Kang HP, Lv HW, Zhang X, Gao FQ et al (2016) Evaluation of the ground response of a pre-driven longwall recovery room supported by concrete cribs. Rock Mech Rock Eng 49:1025-1040

Listak J, Bauer E (1989) Front abutment effects on supplemental supports in pre-driven longwall equipment recovery rooms. In: The 30th U.S. symposium on rock mechanics, Morgantown, WV, 19-22 Jun, pp 693-703

Lv HW (2014) The mechanism of stability of pre-driven rooms and the practical techniques. J China Coal Soc S1:50-56 (in Chinese)

Oyler D, Frith D, Dolinar DR, Mark C (1998) International experience with longwall mining into pre-driven rooms. In: Proceedings 17 th international conference on ground in mining, Morgantown, WV, 4-6 Aug, pp 44-53

Shu CX, Jiang FX, Han YW, Li D et al (2018) Long-distance multicrosscut rapid-retracement technique in deep heavy fully mechanized face. J Min Saf Eng 3:473-480 (in Chinese)

Tadolini, SC (2003) Ground control support considerations for predriven longwall recovery rooms. Ph.D. Dissertation submitted to College of Engineering and Minerals Resources, West Virginia University, Morgantown, WV, p 163

Tadolini SC, Barczak TM (2006) Design parameters of roof support systems for pre-driven longwall recovery rooms. In: SME annual meeting and exhibit, pp 1-13

Tadolini SC, Barczak TM (2008) Rock mass behavior and support response in a longwall panel pre-driven recovery room. In: The 6th international symposium on ground support in mining and civil engineering construction, pp 167-182

Tadolini SC, Barczak TM, Zhang Y (2003) The effect of standing support stiffness on primary and secondary bolting systems. In: Proceedings of the 22nd international conference on ground control min, Morgantown, WV, pp 300-307

Wang XZ, Ju JF, Xu JL (2012a) Theory and applicable of yield mining at ending stage of fully-mechanized face in shallow 
seam at Shendong mine area. J Min Saf Eng 3:151-156 (in Chinese)

Wang XZ, Xu JL, Zhu WB, Ju JF (2012b) Influence of high mining speed on periodic weighting during fully-mechanized mining in a shallow seam. J China Univ Min Technol 3:349-354 (in Chinese)
Wichlacz D, Britten T, Beamish B (2009) Development of a predriven recovery evaluation program for longwall operations. In: Coal 2009: coal operators' conference. University of Wollongong \& the Australasian Institute of Mining and Metallurgy, 12-13 Feb, pp 23-36 